\title{
Is there any hope for 'truth' and 'progress' in theological thinking today?
}

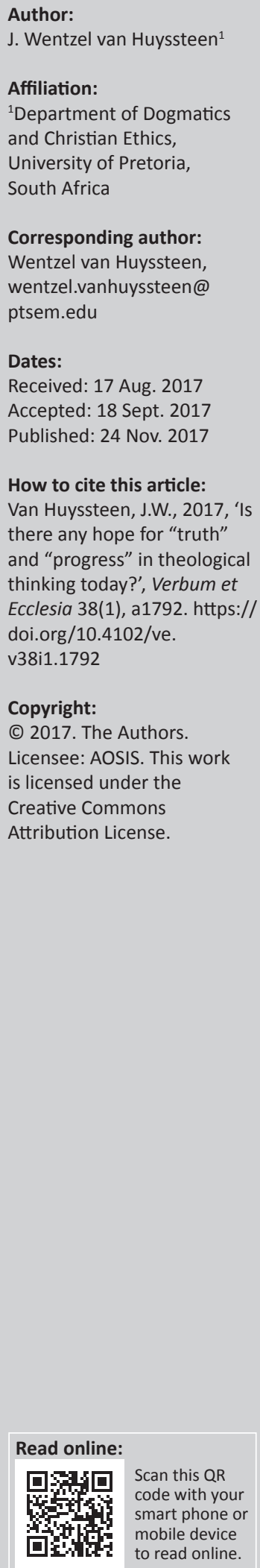

To provide the historical-theological background to his own intellectual pursuit of interdisciplinary theology, Wentzel van Huyssteen tells his story that was prompted in his student days at Stellenbosch by the then young, newly appointed lecturer Johan Heyns. It sprung from the basic understanding and confrontation with the question: How is theology to be understood as a science? The very question became Van Huyssteen's most basic research question for his academic career, guided by the deep conviction that Heyns adamantly proclaimed, namely that the content and methodology of theology could never be deduced from 'the truth of revelation' itself, but would in fact always be shaped by 'a general theory of science'. For Van Huyssteen, this conviction pointed directly to the tentative and hypothetical nature of all theology. It helped him to put into words what would eventually become the defining character of his own theology, namely seeing the intellectual context of theology as a deeply cultural and contextual venture in which the sciences, politics and philosophy would play a defining role. This role is explicated in the article by focusing firstly on the structure of theological solutions, secondly on interdisciplinarity as challenge, subsequently on continuity and change, and lastly on problem-solving within a post-foundationalist theology.

Intradisciplinary and/or interdisciplinary implications: A post-foundational approach argues for the interdisciplinary character of theology as science. The approach transcends traditional boundaries of theological, philosophical and social reflection, establishing an intellectual context of theology as a deeply cultural and contextual venture.

\section{Introduction}

The year 1966 turned out to be an unusually eventful year in my 'then' young life: I got into the final year of my 6-year long adventure as a theology student at the University of Stellenbosch; it was the year in which I also finished my Master's Thesis in Philosophy, and most importantly, it was also the year that I married Ms Hester Theron in the beautiful Dutch Reformed Mother Church at Stellenbosch. However, theologically, 1966 was also an important year for quite a different reason: it was the year in which Johan Heyns 'breezed' into our young lives at the Stellenbosch Kweekskool with a strong personal presence, and even stronger theological convictions. Quite a few of us felt that we were awoken from our 'dogmatic slumbers': this dynamic young professor was actually asking us to think differently by not only asking 'what is theology?' but by restating this important question in several new ways: what is the nature of a theological statement? What is the capacity and range of a theological statement? How reliable are our theological statements, and how can we ever justify or answer the political and epistemological questions these kinds of serious questions were putting on the table? Those of us who were also studying philosophy at the time, however, already knew that these kinds of questions were part of a much broader 1970s intellectual phenomenon where in the philosophy of science not only philosophers of science but also scientists themselves were asking about the nature and identity of a wide range of disciplines.

Theology, of course, could not escape this trend. Especially, Protestant theology in this time soon started - again! - discussing questions like 'is theology a science?'. However, this new theoretical awareness forced Reformed Theology in especially South Africa, Germany, The Netherlands and in some parts of the United States of America, not only politically, but also theoretically and hermeneutically, to question its rather unique and remarkable claims to truth regarding Holy Scripture and to what was seen at the time as God's 'revelation' and God's 'will'. Much of this, on the theoretical and philosophical side at least, seemed to emerge from a clear but extremely problematical contrast between 'faith' and 'reason', and thus between 'authority' and 'rationality'.

Note: This article represents the reworking of the paper delivered by Wentzel van Huyssteen at the Johan Heyns Memorial Lecture on 25 May 2016 at the University of Pretoria. 
This broader metatheoretical context finally set the stage in 1974 for the publication of Johan Heyns and Willie Jonker's important book, Op Weg met die Teologie (1974). Soon after that, in 1978, I attended for the first time a meeting of the South African Theological Society ('Dogmatologiese Werkgemeenskap') in Stellenbosch and delivered a lengthy, fairly critical paper on the relationship between theology and methodology, focusing quite specifically on Heyns' more philosophical contribution to this book (cf. Van Huyssteen 1978). With both my former professors, Johan Heyns and Willie Jonker, in attendance, I had hoped that this moment would lead to a broader and deeper engagement with the question of what a South African version of Reformed Theology might look like in the 1970s. Needless to say, this question was already then driven by both epistemological and political concerns.

I obviously do not intend now to return to my own paper at the time after 40 long years, but there is no doubt in my mind that $\mathrm{p}$ Weg met die Teologie, and the many conversations with Johan Heyns that preceded this book in Amsterdam and Pretoria, would have a rather decisive influence on the critical development of my own interdisciplinary theology, and what we soon - in South Africa, Western Europe, and the United States of America - started calling Philosophical Theology. Although I never could find myself in Heyns' brand of Reformed Theology and Neo-Calvinist philosophy, it was still the best thing around at the time. Moreover, his deep conviction that the content and methodology of theology could never be deduced from 'the truth of revelation' itself (cf. Heyns 1974:14), but would in fact always be shaped by 'a general theory of science', for me already then pointed directly to the tentative and hypothetical nature of all theology, and helped me put into words what would eventually become the defining character of my own theology: seeing the intellectual context of theology as a deeply cultural and contextual venture in which the sciences, politics and philosophy would play a defining role. This enabled me directly to connect theology to contemporary philosophy of science, then and now, and theology for me at that point, true to its Reformed roots, became interdisciplinary theology. Today, of course, it is impossible to know how far Johan Heyns would have followed me and others down this road, but he certainly inspired this radical turn in my own theological journey. I would like to pay attention, firstly, to the structure of theological solutions and, secondly, to interdisciplinarity as a challenge.

\section{The structure of theological solutions}

Today much of the current discussion about the nature of theology is not only focusing on the important role of religion(s) and the sciences in the shaping of quite specific world views, but is slowly but surely also shifting attention to the powerful effect of the so-called science and religion debate on public discourse today. This follows not only in the wake of quite remarkable media attention to exotic debates on issues like evolution, and intelligent design, but also results from an increasing awareness that fundamentalist religious views that want to uphold the alleged superiority of extreme theological conservatism on especially political and sexual or ethical issues are (philosophically, at least) remarkably similar to the views of scientists who believe that there are no real limits to the competence of science. In opposition to these overtly ideological views that place the sciences and religion on a direct collision course, some of us are now arguing for more nuanced and multi-dimensional approaches to interdisciplinary dialogue that take seriously the contextual, social and historical dimensions of both the sciences and religion (and more specifically Christian theology here). This multi-dimensional approach means that any interdisciplinary dialogue between the sciences and theological reflection should not only be grounded in contextual and historical studies of the actual practices of scientific and religious belief (cf. Stenmark 2004:17ff.), but also focus on the actual real-life scientist(s) or theologian(s) who are venturing forth into the unknown and risky waters of interdisciplinary dialogue.

In my own recent work on interdisciplinarity, I have, from a philosophical point of view, rejected the idea that the domain of religious faith and the domain of scientific thought are in any sense exemplified by rival or opposing notions of rationality (cf. Van Huyssteen 1999, 2006). On an epistemological level, this modernist mode of inquiry was of course definitively challenged first by Michael Polanyi, then by Thomas Kuhn and post-Kuhn by various strands of postmodern science. What this move has made increasingly clear is that all our inquiry and reflection, whether scientific or theological, is indeed highly contextual and already presupposes a particular theoretical, doctrinal or personal stance and commitment (cf. Van Huyssteen 1989:47-71, 1999:1-60). For theology the challenge is even more daunting: even if it wanted to, can a theology that has, however, willingly abandoned all grand claims to a-historical, comprehensive all-inclusivity in a conscious shift to contextuality and locality ever be a legitimate part of a multi-dimensional interdisciplinary conversation? Why would the theologian try to speak publicly? And who would care to hear this voice?

\section{Interdisciplinarity as a challenge}

I have argued that Christian theology, by virtue of its quite specific disciplinary identity and the resulting responsibility to engage in public discourse, can access this level of public engagement only through a carefully crafted model for interdisciplinary reflection (cf. Van Huyssteen 1999, 2006). In the kind of multi-dimensional, integrative interdisciplinary conversation that I will argue for, terms such as 'transversality' and 'contextuality' will take centre stage, and will have the value of identifying shared concerns and points of agreement, and maybe more importantly, of exposing areas of disagreement and putting into perspective a methodology for discussing specific divisive issues. We also need to keep in mind that in any interdisciplinary conversation different discourses often represent radically diverse perspectives, and also different and distinct methods of investigation, 
which means they cannot be reduced to each other or derived from each other (cf. Van Huyssteen 1999:235ff.).

As a first step, therefore, I would define as interdisciplinary discourse any attempt to connect or bring together disciplines or reasoning strategies that may have widely different points of reference, different epistemological foci and different experiential resources. This 'fitting together' is always a complex, multi-levelled and transversal process that does not take place within the confines of any given discipline (cf. Changeux \& Ricoeur 2000:87), but, as will become clear, within the transversal spaces between disciplines. In my recent work, I have also argued that all the many faces of human rationality relate directly to a pre-theoretical reasonableness, a 'common sense rationality' that informs and is present in all our everyday goal-directed actions. The origins of a rationality of interdisciplinarity, therefore, lie not in abstract theories of reason but in the everyday and ordinary means by which we make rational judgements and decisions, that is, the performance of embodied rationality in everyday life. From these everyday activities in ordinary time, we can identify epistemic values like intelligibility, discernment, responsible judgement and deliberation, which guide us when on an intellectual level we come to responsible theory choice and commitment (cf. Van Huyssteen 1999:171). It is in the pursuit of these goals and ideals that we become rational persons as we learn the skills of responsible judgement and discernment, and where we articulate the best available reasons we have for making what we believe to be the right choices, those reasons we have for holding on to certain beliefs, and the strong convictions we have for acting in certain ways. More specifically, I have argued that our interdisciplinary reflection and the specialised forms of knowing it presupposes in reasoning strategies such as theology and the sciences differ from other ways of knowing and everyday knowing only in degree and emphasis. All our knowing is grounded in embodied, interpreted experience and is accountable to many layers of interpreted experience, and the adequacy of this accountability is subject to rational justification as justification through interpersonal expertise. These problem-solving judgements apply to both theology and the sciences as we use the same kinds of interpretative and evaluative procedures to broadly understand nature, humans and the social, historical and religious aspects of our lives. And in this fact is found the deepest epistemological and hermeneutical reasons why theology by its very nature should be seen as public, interdisciplinary theology.

In my own recent work, therefore, I have been deeply involved in trying to construct plausible ways for theology to enter into important interdisciplinary conversations. In this venture, we should be wary of any kind of ideological expansion of theological descriptions or of Darwinian explanations, and over against these kinds of reductionist approaches, rather allow for a multi-layered series of explanations that allow a richer and more adequate account of what we typically do and believe. Indeed, no one isolated approach or discipline and no grand, big materialist explanation for religion and for religious faith can ever provide a complete account of the complex phenomena we encounter in contemporary interdisciplinary theology. On this view, scientific and religious rationalities should be evaluated while including emergent and non-reductionist types of descriptions and explanations that also employ personal, moral, aesthetic and religious categories.

As a way of facilitating this kind of cross-disciplinary dialogue, I have argued for a post-foundationalist approach to interdisciplinary dialogue, which implies three important moves for theological reflection. Firstly, as theologians we should acknowledge the radical contextuality of all our intellectual work, the epistemically crucial role of interpreted experience and the way that disciplinary traditions shape the values that inform our reflection about God and what we believe to be God's presence in the world. Secondly, a postfoundationalist notion of rationality should open our eyes to an epistemic obligation that points beyond the boundaries of our own discipline, our local communities, groups or cultures, towards plausible forms of interdisciplinary dialogue (cf. Van Huyssteen 1999). Against this background I have argued for distinct and important differences between reasoning strategies used by theologians and scientists. I have also argued, however, that some important shared rational resources may actually be identified for these very different cognitive domains of our mental lives (cf. Van Huyssteen 2006). Thirdly, it is precisely these shared rational resources that enable interdisciplinary dialogue and are expressed most clearly by the notion of transversal rationality. In the dialogue between theology and other disciplines, transversal reasoning promotes different, non-hierarchical but equally legitimate ways of viewing specific topics, problems, traditions or disciplines, and creates the kind of space where different voices need not always be in contradiction, or in danger of assimilating one another, but are in fact dynamically interactive with one another. This notion of transversality thus provides a philosophical window to our wider world of communication through thought and action (cf. Schrag 1992:148ff.; Welsch 1996:764ff.) and challenges us to construct bridge theories between disciplines, while respecting the disciplinary integrity of reasoning strategies as different as theology and the sciences. In this way, an interdisciplinary approach, carefully thought through, can help us to identify these shared resources in different modes of knowledge so as to reach beyond the boundaries of our own traditional disciplines in crosscontextual, cross-disciplinary conversation. It can also enable us, as will become clear, to identify possible shared conceptual problems as we negotiate the porous boundaries of our different disciplines.

If we take the evolution of human knowing or cognition seriously, we quickly realise that even theological reflection is radically shaped by the enduring influence of its own traditions, and therefore by its social, historical and cultural embeddedness. However, this would imply that theology, and theological reflection and knowledge, is not only shaped by cultural evolution, but is also definitively shaped by the deeper biological roots of human rationality. This is precisely 
the point made by evolutionary epistemology: like all living beings we humans have resulted from evolutionary processes and, consequently, our mental capacities are constrained and shaped by the mechanisms of biological evolution.

On this view, all evolutionary epistemologists agree that the theory of evolution in essence is a theory of knowledge precisely because the process of evolution is the principal provider of the organisation of all living things and their adaptations (cf. Wuketits 1990). Evolution thus turns out to be about much more than the 'origin of species' and is revealed as a much richer process that has shaped the way our minds work, and how we know the world. As such, evolutionary epistemology highlights both the deeply embodied and the fallibilist nature of all human knowledge, and explains that there are advances and growth in human knowledge, but that this 'progress' is not necessarily an increase in the accuracy of depiction or an increase in the certainty of what we know. This view is strengthened by the conviction that human knowing or cognition is a crucial bridge between biology and culture, between biological evolution and cultural evolution. And this is exactly what contemporary discussions of extended notions of evolution like niche construction are focusing on.

From a philosophy of science perspective, scholars often, and correctly I would argue, see evolutionary epistemology as an important but somewhat neglected reaction to the failure of logical positivism. Positivism is widely seen today as failing to account for the growth of human knowledge, for major shifts in the history of science (like the shift from Newtonian physics to Einstein's general relativity), in the history of theology (like the dramatic shift from Medieval scholastics to the Reformation), or general paradigm shifts in cultural history (for instance, from modernity to postmodernity). What is often ignored, however, is the fact that there occurred two very different and competing moves away from positivistic philosophy of science: one move was towards Wittgenstein's philosophy of language games and Thomas Kuhn's now-famous theory of paradigms; the other move was towards Karl Popper's evolutionary epistemology and the all-important injection of Darwinism into philosophy or philosophy of science. Thus, in addition to the acknowledgement of the theory-ladenness and paradigm dependency of knowledge in the first instance, evolutionary epistemology seeks to explain the knowledge we have as an extension of the adaptive evolutionary process of knowing that began millions of years ago. I would argue that both these very important reactions to positivist views of human knowledge, in very different ways, opened our eyes to the intuitive, interpretative and hermeneutical dimension of all knowledge. It should, therefore, not be surprising that in contemporary post-foundationalist views of knowledge, hermeneutics and epistemology would powerfully merge.

The interactionist nature of all human knowing, because of its deep biological history, thus emerges as a deeply embodied knowledge. And through our language abilities we have created cultures and a vast body of knowledge: these can be seen as evolutionary artefacts that enable us to benefit from the trials and errors of our ancestors. Or, as some evolutionary epistemologists would put it: with the arrival of Homo sapiens, human evolution became the evolution of this embodied knowledge. On this more embodied, holistic view of human knowing, not only are narrowly conceived notions of reason or rationality included, but also human consciousness becomes more richly redefined in terms of feelings, intuitions, emotions, instinct and intelligence. Thus, one of evolutionary epistemology's most valuable contributions to notions of biological and cultural evolution becomes clear: once embodied intelligence evolved in our species, our self-conscious brains achieved a causal force equal to that of our genes.

On a cultural level, and for Christian theology as part of a long tradition in the evolution of religion, evolutionary epistemology 'sets the stage', as it were, for understanding the deep evolutionary impact of our ancestral history on the evolution of culture, and eventually on the evolution of disciplinary and interdisciplinary reflection: in the process of the evolution of human knowledge, our interpreted experiences and expectations of the world (and of the ultimate questions we humans typically pose to the world) have a central role to play. I have argued strongly for the fact that we humans relate to our worlds through our interpreted experience (hermeneutics), and that our questions, expectations and our beliefs are always based on these interpreted experiences, which in turn lead us not only to new expectations but also to finding good reasons for holding all-important beliefs about ourselves and our world (epistemology). Evolutionary epistemology helps us to understand this all-important connection as a result of a longterm evolutionary process (cf. Van Huyssteen1989, 2006).

What evolutionary epistemology shows us, finally, is that we humans can indeed take on cognitive goals and ideals that cannot be explained or justified in terms of survivalpromotion or reproductive advantage only. Therefore, once the capacities for rational knowledge, moral sensibility, aesthetic appreciation of beauty and the propensity for religious belief have emerged in our biological history, they cannot be explained only in biological or evolutionary terms. In this sense, we clearly transcend our biological origins and have the ability to transcend what is given to us both in biology and culture. As British philosopher Anthony O'Hear strikingly puts it: we are prisoners neither of our genes, nor of the ideas we encounter as we culturally make our way through the world (O'Hear 2002:vii).

\section{Continuity and change in research traditions: Niche construction in theology, philosophy and science}

It is especially interesting to note how most scholars today also acknowledge and accept a 'hierarchical progression' model of the evolution of symbolic and semiotic capabilities in humans (cf. Donald 2001; Mithen 2009; Noble \& Davidson 1996; Robinson 2010). Andrew Robinson (cf. Robinson 2010:147) in particular has suggested that the three main 
assumptions behind these hierarchical approaches to human evolution and to human semiotic competence can be seen as follows:

- The evolution of human semiotic capability moves, in some sense, from the use of simple to more complex and sophisticated signs.

- The culmination of this process is the capacity for using symbols.

- Once this capability has been acquired, further developments in human evolution may follow from the possibility of using symbols in novel ways.

Implied in views like these is of course the fact that Darwinism is itself evolving. Andrew Robinson has focused in his work on the well-known 'three phases of evolution': the first major historical phase that stretched from the publication of the Origin of Species and lasted into the early 20th century, the second phase that culminated in the 'Neo-Darwinian synthesis' and the combination of natural selection with Mendelian genetics and the third phase that originated around the 1970s with various pressures on the Neo-Darwinian synthesis, notably Gould and Eldridge's thesis for a 'punctuated equilibrium' that directly challenged conventional evolutionary gradualism (cf. Robinson 2010:182ff.). Robinson also helpfully suggests that these three phases in Darwinian evolution broadly correspond with three key themes in the history of evolutionary thinking: the theme of evolutionary continuity which arose particularly in the first phase of Darwinism, when the theory of 'descent with modification' became widely accepted in scientific circles; the theme of ontological naturalism which arose especially from the second phase of Darwinism, when the NeoDarwinian synthesis demonstrated the power of natural selection as an evolutionary mechanism; and, finally, the theme of historical contingency, which has been much informed by new insights into complex system dynamics and the loosening up of 'adaptationist' thinking in biology.

What does seem interesting is that an inherent feature of niche construction as an elementary evolutionary fact seems to be that, in contrast to other mechanisms like selection or gene drift, niche construction indeed does seem to introduce a certain directedness into the evolutionary process (cf. Olding-Smee, Laland \& Feldman 2003:33; also Mühling 2014:147). For Mühling this kind of directedness which niche construction adds to the process of evolution is a nonteleological one, but it is a kind of information related to purpose and 'semantic information', and by 'semantic information' these biologists mean information that relates to the fitness of specific organisms, their requirements in their local environments, et cetera. One might even say that the niche constructing activities of organisms could be oriented towards targeted future outcomes of organisms-environment interactions on the basis of at least rudimentary and semantically informed search plans (cf. Olding-Smee et al. 2003:177f.). Therefore, in this limited and, in most species, entirely non-cognitive sense, niche construction must be preparative or predictive in character (Olding-Smee, as quoted in Mühling 2014:147).
On this view, then, looking at human origins and the archaeology of personhood, and thus at the evolution of our lineage across the Pleistocene, it is evident that there is significant increasing complexity in the way we interface with the world (cf. Fuentes 2014:9): increases in the complexity of culture and social traditions, tool use and manufacture, trade and the use of fire, as well as enhanced infant survival and predator avoidance, increased habitat exploitation, information transfer via material technologies, which have increased in intensity rather dramatically in the last 400000 years. All of these increasing complexities are linked directly to a rapidly evolving human cognition and social structure that require increased cooperative capabilities and coordination within human communities. Thinking of this as specific outcomes of a niche construction actually provides a mechanism, as well as a context, for the evolution of this multifaceted response capabilities and coordination within communities (cf. Fuentes 2014:9).

I believe one can, therefore, correctly claim that our niche construction framework may provide an all-important interactive bridge that transcends too simplistic distinctions between biological and cultural evolution because it emphasises the active role that organisms play in the evolutionary process. In the case of humans, we are not just passive vehicles for genes, but we actively modify sources of natural selection in environments. Some have even gone so far as to call us humans 'the ultimate niche constructors' (cf. Olding-Smee et al. 2003:27ff.; also see Mühling 2014:162). Mühling is quick to say, however, that we should always remember it is not the organisms themselves that are responsible for the construction of niches, but rather the whole system, including both organisms and environment. To place human beings exclusively in the role of niche constructors would actually contradict the theory and make it more constructivist, a feature never so exclusively inherent in niche construction.

This fact seems unusually important if we also want to talk about the future of human evolution. We thus need to be careful not to anthropomorphise niche construction: to say humans are the ultimate niche constructors not only adds a specific value to niche construction, but implicitly may be taken to actually deny that humans can be succeeded by others in niche construction activity and capability. But to call humans ultimate niche constructors could also implicitly deny that, with regard to temporality, evolution will carry on in significant ways, implying that humans could actually be displaced by other species. Maybe we should rather see ourselves as relatively ultimate niche constructors, that is, as relative to the history of evolution as known to us (cf. also Mühling 2014:163). In fact, to call ourselves ultimate niche constructors might also deny the possibility that something similar might actually still take place at other unknown places in our universe. And if contingency is still part of niche construction as a free, dynamic process of evolution, it certainly prevents us humans from assuming that we could have control of over the process of niche construction. 
In terms of non-teleological directionality, finally, and in terms of our own human constructed niche, the emergence of language and a fully developed theory of mind with high levels of intentionality, empathy, moral awareness, symbolic thought and social unity would all be impossible without an extremely cooperative and mutually integrated social system in combination with enhanced cognitive and communicative capacities as our core adaptive niche. Interestingly, on this point Fuentes himself wants to incorporate an analysis on compassion (cf. Fuentes 2014:10). I believe this can be pushed even further back by tracing the deep evolutionary roots of empathy and attachment (cf. Van Huyssteen 2014). Our genus thus provides a scenario wherein we can envision a distinctively human imagination as a key part of our niche and as a part of the explanation for why our species succeeded and all other hominins went extinct. Fuentes puts it rather forcefully: the imagination and the infusion of meaning into the world by the genus Homo in the late Pleistocene is what underlies, and preceded our current ability to form a metaphysics which in turn eventually facilitates religious beliefs. This landscape of meaning and associated imagination is also a system that facilitates an array of other symbolic and meaning-laden aspects of human behaviour and experiences that are not at the core of our current niche and lives (cf. Fuentes 2014:11). Important though, there is no single trait that explains human evolutionary success, nor is there a particular environment that created it. And part of this significant toolkit includes a robust imagination and a landscape and perceptual reality wherein everything, whether material or not, is infused with multifaceted meaning.

At the heart of this then is the increasingly rapid and dynamic niche construction by humans, particularly as it relates to aspects of cognitive and symbolic function and social relationships, and the imaginative ability to deploy multiple modes of responding to evolutionary pressures. Fuentes is here in agreement with Deacon (1997), Donald (2001), King (2007), Barnard (2012) and Andrew Robinson (2010) that it is our place as a semiotic species, and the use of symbol as a core infrastructure of our perceptions in our perceptions of and dealing with the world, which act as a major factor, and thus as a hallmark of human evolution (cf. Fuentes 2014:12).

Humans have an imagination that is part of our perceptual and interactive reality and is a substantive aspect of lived experience. Thus, it is realistic to accept that at some point in the last 400000 years language and hyper-complex intentionality acted to 'lock-in' the more-than-material as our permanent state of being and so laid the groundwork for the evolution of morality, the possibility of metaphysics, aesthetic propensities, religious imagination and the propensity for religious belief (cf. Van Huyssteen 2006), as crucial parts of the uniquely human experience. Now existing in a landscape where the material and social elements have semiotic properties, and where communication and action can potentially be influenced by representations of both past and future behaviour, implies the possession of an imagination, and even something like 'hope', that is, the expectation of future outcomes beyond the predictable (cf. Fuentes 2014:13). The assertion here is, then, that this interactive process occurs as a component of the human niche as it moves dynamically through the Pleistocene as part of the emerging human toolkit.

Importantly, imagination, and therefore, religious imagination, on this view is not just an exaptation, a spurious by-product of evolution, but crucial to the process of human evolution and incorporates behavioural processes and a sense of imagination and hope that would, and did, increase the likelihood of innovation and successful responses to evolutionary challenges (cf. Fuentes 2014:14). This also implies that human distinctiveness may have emerged not merely through the ascent of a hierarchy of semiotic competence, of which symbolic competence was the pinnacle, but, rather, through the entering of what Andrew Robinson refers to as the semiotic matrix (cf. Robinson 2010:150f.). In the Upper Paleolithic in Europe, and probably earlier in Africa (cf. Van Huyssteen 2006:217-270), anatomically modern humans crossed a new cognitive threshold into a semiotic realm, a threshold of semiotic competence that allowed for the combination of remarkable new forms of symbolic communication.

This brief review of human origins and human evolution demonstrates the path and substantive impact of changes in behaviour, life histories and bodies in our human ancestors and us humans ourselves. From this, it is clear that patterns that in the Upper Paleolithic would lead to the unambiguous appearance of 'art' and 'symbol', now also combined with the evolution of empathy and compassion and the deep caring for others (cf. Boehm 2012; Fuentes 2014; Van Huyssteen 2014). It should therefore not be surprising that a distinctively human imagination is part of the explanation for human evolutionary success and can be seen as one of the structurally significant aspects of the transition from earlier members of the genus Homo to ourselves as we are today.

On this view it now quickly becomes clear that there are no easy 'blue prints' available today for 'doing science and theology'. In fact, the rationality of a post-foundationalist theology, like science, relies on a community, a community that not only converses with itself but also seeks to engage in dialogue across disciplines because of the relational resources that these various research strategies share. In this way, a door is opened for seeing problem-solving as a central activity of research traditions. And as philosopher of science Larry Laudan has argued, one of the most important shared rational resources between even widely divergent disciplines is problem-solving as the most central and defining activity of all research traditions (cf. Laudan 1977:190ff.; Van Huyssteen 1989:172-89, 1999:164ff.). And as will become clear, the very diverse reasoning strategies of theology and the sciences clearly overlap in their shared quests for intelligible problemsolving, including problem-solving on an empirical, experiential or conceptual level. 
As an important step beyond any universalist and generic notions of rationality, I have argued for developing a postfoundationalist notion of rationality, where, as rational agents situated in the rich, narrative texture of our own social practices and traditions, our self-awareness and our self-conceptions are not only intrinsically embedded in our own embodied rationality, but also are indeed indispensable starting points for an account of the values that shape human rationality. This explains why in theology, as well as in the sciences, our traditions, paradigms and world views, like all other traditions, are historical creatures. The identity and integrity of any tradition is preserved in what we may call its heart or canon, which normally functions as an authoritative narrative and conceptual framework that shapes and moulds continuity and change in traditions as lived realities. And as historical creatures, also our intellectual traditions can wax and wane. Larry Laudan has convincingly pointed out (cf. Laudan 1977:77ff.) that Thomas Kuhn's famous notion of a radical paradigm shift or conceptual 'conversion' or 'revolution' from one paradigm to another can most probably be seen as a natural evolution within and between research traditions. Traditions, therefore, not only imply ongoing change and evolution but also exhibit continuity. Precisely, continuity and change then should be seen as the primary categories of any adequate theory of traditions, especially in theology.

To understand what continuity and change might mean in the dynamics of evolving traditions, Larry Laudan, like Imre Lakatos (1970), suggests that certain elements of a research tradition are sacrosanct and cannot therefore be rejected without a repudiation of the tradition itself. Unlike Lakatos, however, Laudan insists that what is normally seen as sacrosanct in traditions can actually change with time. From recognising that the canonical core of traditions can actually shift and change over time, Laudan can then conclude that by relativising the 'essence' or core of a research tradition with respect to place and time, we actually come closer to capturing the way that scientists and historians of science have used the concept of tradition (cf. Laudan 1977:99f.). For me this not only reveals again the radical historical nature of all traditions, but also that intellectual revolutions do not necessarily take place through complete conceptual shifts, but rather occur through the ongoing transversal and interdisciplinary integration and grafting of (research) traditions.

On a post-foundationalist view, then, and because we are deeply embedded in the history of our times, our research traditions in a sense constitute the present and finally explain why we relate to our world epistemically through the mediation of interpreted experience. Our intellectual traditions are therefore dynamic, evolving phenomena that live precisely in the dialectic of continuity and change. And like cultural traditions, research traditions are rarely, if ever, isolated from one another because the borders separating traditions from their milieus and from other traditions are always exceedingly porous (cf. Brown 1994:26f.). This makes continuity and change in traditions even more intelligible: all traditions, as we have seen, have sacrosanct elements that, even if they shift and change over time, form the canons of these traditions and ultimately define their identity. It is these core canons of traditions that ultimately serve as the sources of creativity as well as the principles of identities of traditions.

This post-foundationalist view of rationality and the way it reveals the structure and functions of traditions clearly have important consequences for theological reflection. It also shows why any uncritical retreat to a fideist commitment to a specific tradition and its canon(s) would seriously jeopardise the epistemic status of theological reflection as a credible partner in a pluralist, interdisciplinary conversation. Within a fideist context, all commitment and religious faith seem to be irrevocably arbitrary. However, the most serious limitation to any fideist epistemology would be its complete inability to explain why we choose certain viewpoints, certain networks of belief and certain traditions over others. Surely there must be more to religious commitment, and to using theological language, than to just understanding and adopting the internal working of some specialised linguistic system that is not answerable to anything or anybody outside itself (cf. Van Huyssteen 2006:28f.).

\section{Problem-solving and progressive theory choice as the hallmark of a post-foundationalist theology}

The kind of epistemological fallibilism that naturally follows from a post-foundationalist approach to interdisciplinary theology will, therefore, not result in that one, ideal modernist knowledge system for systematic theology or for research programs in theology and science. Instead of the one perfect representation of God, or of the world, or of God's relation to the world, however, it may yield for us a collage of knowledge claims that aims to be the most adequate, the most reliable and, for now, the most meaningful we can claim in certain specific contexts. However, the fact that there are no longer any pre-set, foundationalist, universal, cross-cultural or interreligious rules for science or for theology does not necessarily mean that all our criteria for good reliable knowledge are now always going to be only strictly local or exclusively contextual. In Delwin Brown's words: if none of our criteria were to be acceptable beyond the boundaries of a specific research tradition, then the giving of rational reasons beyond the boundaries of any tradition would be impossible (cf. Brown 1994:6).

The crucial problem for a theology located in interdisciplinary conversation therefore remains the following: how do we distinguish between 'good' theology and 'bad' theology, and is it at all possible to make sensible and rational choices between different viewpoints and alternative, competing research traditions? At this point, Larry Laudan's admonitions to scientists and theologians again come to mind: unless we can somehow articulate criteria for choice between diverse research traditions, we neither have a theory of rationality nor a theory of what progressive growth in knowledge should look like (cf. Laudan 1977:106). In theology, as in other forms of inquiry, providing warrants for our views thus becomes a cross-contextual obligation (cf. Brown 1994:6f.). 
Remarkable parallels are now surfacing here between the rationality of theology and other modes of knowledge. A good example is again found in reasoning strategies as different as theology and the sciences: in both we are called to trust our traditions as we reach out beyond them in interdisciplinary conversation (cf. Van Huyssteen 1998:28ff.). In both theology and the sciences, we should be able to identify some criteria to warrant our theory choices, and neither scientific nor theological knowledge can ever claim demonstrably certain foundations for making these choices. Epistemic similarities between theology and the sciences do not mean, of course, that scientific knowledge is 'just like' theology, but they do mean that methods in science do not provide us with a uniquely rational and objective way of discovering truth. In both theology and the sciences, good arguments should therefore be offered for or against theory choice, or for or against the problem-solving ability of a specific research programme. Obviously, our good arguments and our value judgements rest on broader assumptions and deeper commitments which can always again be challenged. This does not mean, however, that any opinion is as good as any other, or that we can never critically compare radically different points of view. What all of this does mean, however, is that we certainly seem to be in need of a more comprehensive epistemological programme, which can facilitate and create an interdisciplinary space that would not be totalising in any reductionist sense of the word.

Problem-solving and progressive theory choice, therefore, go together closely in a post-foundationalist theology. Implied in this claim is one of the most important criteria for 'good theology': through our theological statements, we should be able to critically identify and analyse real problems, and to construct theories that might provide valid and adequate solutions to those problems (cf. Van Huyssteen 1989:172ff.). This not only includes a critical analysis of the process of theorising in interdisciplinary theology, but also challenges theologians to think anew about the following concrete questions:

- What would qualify as a problem in theology?

- What would qualify as a problem in interdisciplinary theology?

- What constitutes a shared interdisciplinary problem in theology and the sciences?

- What is it that sometimes makes one problem more important than another problem in interdisciplinary reflection?

- How would scientific problems be similar to and different from problems in theology?

- What constitutes problem-solving in interdisciplinary theology?

- What criteria would be valid for a converging process of problem-solving in theology and the sciences?

- How are interpretative styles of problem-solving in theology similar to or different from explanatory styles of problem-solving in the sciences?

In contemporary philosophy of science, Larry Laudan, in particular, has offered a model for scientific problem-solving, progress and rationality that has proven to provide important links to problem-solving in theological reflection, and thus by implication - would be valuable in our thinking through the issue of problem-solving in interdisciplinary theology. Like Thomas Kuhn, Laudan has sought to demonstrate that important non-empirical, even non-scientific factors play a key role in rational development. Similarly to Kuhn, Laudan has argued that the rationality and ultimate progressiveness of a specific theory are closely related not in terms of a positivist notion of justification, or even a Popperian notion of falsification, but rather in its capacity for effective problemsolving in a given context. Different from Kuhn, Laudan points out that scientific progress is not so much only a matter of problem-solving in specific theories, but also the potential for scientific progress and the growth of knowledge in global theories, which he has specifically called research traditions (cf. Laudan 1977:106ff.).

Importantly, then, Laudan has argued persuasively that scientific and other problems are not all that different, and that the differences are often not a difference in kind, but largely a matter of degree. In fact, he has shown that his perspective in scientific problems could, with a few qualifications, be applied to all forms of intellectual problems (Laudan 1977:13). On a post-foundationalist view, this would meant that the focus now is on the analysis of problems as the true focus of scientific as well as theological thought. Theories then are important only in so far as they offer adequate solutions for real problems. On an interdisciplinary level, this means that if problems constitute the real questions of science (and of theology), then it is theories (and in theology, theories and doctrines) which constitute the answers or solutions.

For theologians, this means that we have to learn to identify real problems that arise out of religious, political and spiritual experience, including the intellectual problems that emerge out of a reflection on these problems. This implies a deeply liberating move for theological reflection: by reclaiming a broader post-foundationalist notion of rationality, theologians are now freed from reductionist models of rationality. Instead of having to ask whether a given theory is provable, correct, justified or true, they can now first ask whether a theory offers adequate solutions for meaningful, real problems in concrete situations.

Laudan has also argued, as is well known, that scientific theories have to cope with mainly two kinds of problems, and he states explicitly that this model might also be applied to theological reflection. I have reworked this distinction within the wider scope of a post-foundationalist model for theology and revisioned it as now including interdisciplinary problems (cf. Van Huyssteen 1999, 2006). These two types of problems we can now identify as empirical and conceptual problems (cf. Laudan 1977:110f.), and these concepts finally get us to Laudan's definition of intellectual (scientific and theological) progress: for science it means that scientific progress is the solving of empirical problems, and the transformation of unsolved problems into ones that have been solved as effectually as possible (cf. Laudan 1977:120). 
Laudan, however, states that 'determinations of truth and falsity are irrelevant to the acceptability or the pursuitablility of theories or research traditions' (Laudan 1977:120).

In all fairness, however, and important for the constructions of theories in theology, Laudan suggests that his problem for progressive problem-solving does not in principle exclude the possibility that scientific theories might be true, or might even be advancing towards the truth (cf. Laudan 1977:126). What he wishes to avoid, however, is some utopian nearerto-the-truth ideal, something which is in any event not scientifically ascertainable.

On exactly this point I think theology has much to learn in thinking more pragmatically about the concrete capacity of theories for finding adequate and meaningful solutions for interdisciplinary problems, instead of obsessing about truth claims per se. This does not take away at all from the fact that we have good reasons to believe in the constructive and progressive quality of the statements in interdisciplinary theology. From a post-foundationalist viewpoint, this means finding the best available interdisciplinary reasons for making the most progressive theory choices, and thus guaranteeing a theory of intellectual growth. As to the reality of what we are referring to in our theory choices on a post-foundationalist view, in developing a criterion for progress, we will in principle have to leave room for tentative, critical or hypothetical references to the reality status of that with regard to which we believe our problems are solved progressively.

As regards the status of problems in interdisciplinary problems, an empirical problem might be anything that strikes us as unusual, and thus as calling for an explanation within, firstly, the Christian paradigm and, secondly, within an interdisciplinary research paradigm. I have argued that the following might be identified as examples of empirical problems for interdisciplinary theology: the reality of evil or sin, the meaning of suffering of death in the light of faith in a good, loving God, the experiential basis of faith and the problems it causes in questioning the presence and action of God in daily life, ethical and sociopolitical questions, et cetera. (cf. Van Huyssteen 1989:175). A second problem, however, is as important as empirical ones for the advancement of interdisciplinary reflection in theology and science: this type of problem has already been identified by Kuhn, but has been developed further by Laudan as conceptual problems problems with the specific aim of providing a broader and richer theory of problem-solving than the merely empirical. Insights into these kinds of interdisciplinary problems arise specifically on a conceptual level as a result of interdisciplinary interaction between divergent and especially conflicting theories. Clearly the broad spectrum of issues dealt with in the current theology and science dialogue is a classic example of these kinds of conceptual problems.

Finally, Laudan has also further refined his notion of conceptual problems by helpfully making a further distinction between internal conceptual problems, which arise from apparent inconsistencies or ambiguities within a particular theory, and external conceptual problems, which may arise from direct philosophical conflicts between two theories (the most notorious example being the ongoing conflict between Darwinian evolution by natural selection and 'biblical theories of creation'). These broader problems may have scientific, philosophical, ideological, methodological or specifically religious or theological causes. Laudan's useful distinction between internal and external conceptual problems would in my view need even further refinement, in the sense that what normally could be defined as an empirical problem in theology often hides a more profound conceptual or ideological problem, and what may appear to be internal conceptual problems often reveal more profound external conceptual problems (cf. Van Huyssteen 1989:176). This takes us as close as we can reach at a definition of 'progress' in post-foundationalist, interdisciplinary theology: in the progressive and constructive quality of interdisciplinary theories, it will be the solving, however provisionally, of empirical and conceptual problems that will be at the heart of a model for advancement or 'progress' in interdisciplinary theology. We may also put it as follows: in interdisciplinary theology, too, a theory gains if it can offer provisional solutions to empirical problems; but it loses if it raises more conceptual problems.

\section{Conclusion}

Ihave argued that contemporary forms of post-foundationalist epistemology have convincingly shown that it has become implausible today even to talk about rationality, or even 'theology and science' in any generic, abstract sense. In fact, the radical social and historical contextuality of all our embodied rational reflection reveals that in interdisciplinary dialogue the rather a-contextual terms 'theology and science' should be replaced by focusing our attention on specific theologians, engaging in specific kinds of theologies, who are attempting to enter the interdisciplinary dialogue with very specific scientists, working within specific sciences on clearly defined, shared problems.

The idea that the domain of religious faith and the domain of scientific thought in any sense exemplify rival or opposing notions of rationality should be rejected outright. In fact, different and seemingly incompatible reasoning strategies actually share what I have called the resources of human rationality' (cf. Schrag 1992). For this reason, a postfoundationalist notion of rationality, rightly conceived, should enable us to leave behind abstract, overgeneralised 'blueprints' for engaging in interdisciplinary research and help us to focus on developing, first, contextually and, then, transversally the merits of specific interdisciplinary problems. It is in this sense that a multi-disciplinary approach to specific problems may actually yield interdisciplinary results.

A post-foundationalist notion of rationality thus reveals not only a more holistic, embodied way to think about human rationality but also argues for the public voice of theology in our rather complex contemporary culture. Not only 
theologians but also scientists of all stripes should be empowered to argue for the rational integrity of their own specific disciplines, while at the same time be free to pursue overlapping concerns, identify shared problems, and even parallel research trajectories as they cross disciplinary lines in multi-disciplinary research. Here theology is neither transformed, modernistically, into natural science, nor rejected as non-science. On this interdisciplinary mode, theological reflection emerges as a reasoning strategy on par with the intellectual integrity and legitimacy of the natural, social and human sciences, even as it delineates its own domain of thought that in so many ways is also distinct from that of the sciences. At the heart of this kind of interdisciplinary reflection, therefore, we find a new opportunity: as we find ourselves deeply embedded in specific research traditions, we may now realise that a particular disciplinary tradition may actually generate questions which cannot be resolved by its own resources alone. And it is exactly this kind of interdisciplinary awareness that may lead us to crossdisciplinary boundaries and reach out for intellectual support to other disciplines.

Because of the multi-dimensional, transversal nature of human rationality, we are enabled to enter the pluralist, interdisciplinary conversation with our full personal convictions intact, while at the same time we are theoretically empowered to step beyond the limitations and boundaries of our own contexts, traditions and disciplines. It is in this sense that, in the dialogue between theology and other disciplines, transversal reasoning facilitates different but equally legitimate ways of evaluating issues, problems, traditions or even disciplines themselves. Transversal rationality thus emerges as a performative praxis where our multiple beliefs and practices, our habits of thought and attitudes, and our prejudices and judgements converge. In this way, a postfoundationalist notion of rationality enables us to retain the language of epistemology by fusing it with hermeneutical concerns. Our different genres of discourse can now be performatively integrated by our making of scientific claims, moral statements, aesthetic evaluations, religious judgements and theological assessments. Precisely in revisioning interdisciplinary dialogue as a form of transversal reasoning, human rationality does not have to be identified with isolated and austere forms of reasoning anymore, but as a practical, embodied skill that enables us to gather and bind together the patterns of our daily experiences, and then make sense of them through communal, interactive dialogue.

On this view, Christian theology - in the midst of other 'rationalities' - should be able to claim a public or 'democratic' presence in interdisciplinary dialogue. Here theology will share in interdisciplinary standards of rationality, which, although always contextually and socially shaped, will not be hopelessly culture- and context-bound. This will enable our theological reflection to aim for the reasoned coherence of a wide reflective equilibrium as the optimal epistemic goal of interdisciplinary dialogue. This post-foundationalist approach to interdisciplinarity also reveals interdisciplinary reflection as non-hierarchical because no one disciplinary voice, and no one set of judgements, practices or principles, will be able to claim any absolute priority over, or be foundational for any other.

\section{Acknowledgements Competing interests}

The author declares that he has no financial or personal relationships that may have inappropriately influenced him in writing this article.

\section{References}

Barnard, A., 2012, Genesis of symbolic thought, Cambridge University Press, Cambridge. https://doi.org/10.1017/СВ09781139198707

Boehm, C., 2012, Moral origins: The evolution of virtue, altruism, and shame, Basic Books, New York.

Brown, D., 1994, Boundaries of our habitations: Tradition and theological construction State University of New York Press, Albany, NY.

Changeux, J.-P. \& Ricoeur, P., 2000, What makes us think? A neuroscientist and a philosopher argue about ethics, human nature, and the brain, Princeton University Press, Princeton, NJ.

Deacon, T., 1997, The symbolic species: The co-evolution of language and the brain, Norton, New York.

Donald, M., 2001, A mind so rare: The evolution of human consciousness, W.W. Norton, New York.

Fuentes, A., 2014, 'Human evolution, niche complexity, and the emergence of a distinctly human imagination', Time and Mind 7(3), 241-257.

Heyns, J. \& Jonker, W., 1974, Op Weg met die Teologie, NGKB, Pretoria.

King, B., 2007, Evolving God: A provocative view on the origins of religion, Doubleday, New York.

Lakatos, I., 1970, Criticism and the growth of knowledge, Cambridge University Press, Cambridge. https://doi.org/10.1017/CBO9781139171434

Laudan, L., 1977, Progress and its problems: Toward a theory of scientific growth, University of California Press, Berkeley, CA.

Mithen, S., 2009, The singing Neanderthals: The origins of music, language, mind, and body, Harvard University Press, Cambridge, MA.

Mühling, M., 2014, Resonances: Neurobiology, evolution and theology. Evolutionary Niche construction, the ecological brain and relational-narrative theology, Vandenhhoeck \& Ruprecht, Gottingen. https://doi.org/10.13109/978366 6570360

Noble, W. \& Davidson, I., 1996, Human evolution, language and mind: A psychological and archaeological inquiry, Cambridge University Press, Cambridge, MA.

Olding-Smee, F.J., Laland, K.N. \& Feldman, M.W., 2003, Niche construction: The neglected process in evolution, Princeton University Press, Princeton, NJ.

O'Hear, A., 2002, Beyond evolution: Human nature and the limits of evolutionary explanation, Clarendon, Oxford.

Robinson, A., 2010, God and the world of signs: Trinity, evolution, and the metaphysical semiotics of C.S. Pierce, Brill Publishers, Boston, MA. https://doi.org/10.1163/ ej.9789004187993.i-382

Schrag, C., 1992, The resources of rationality: A response to the postmodern challenge, Indiana University Press, Bloomington, IN.

Stenmark, M., 2004, How to relate science and religion: A multidimensional model, Eerdmans, Grand Rapids, MI.

Van Huyssteen, J.W., 1999, The shaping of rationality: Toward interdisciplinarity in theology and science, Eerdmans, Grand Rapids, MI.

Van Huyssteen, J.W., 2006, Alone in the world? Human uniqueness in science and theology, Eerdmans, Grand Rapids, MI.

Van Huyssteen, W., 1978, 'Teologie en Metode', Koers 43(4), 377-411. https://doi. org/10.4102/koers.v43i4.1172

Van Huyssteen, W., 1989, Theology and the justification of faith: Constructing theories in systematic theology, Eerdmans, Grand Rapids, MI.

Van Huyssteen, W., 1997, Essays in postfoundationalist theology, Eerdmans, Grand Rapids, MI.

Van Huyssteen, W., 2014, 'From empathy to embodied faith: Interdisciplinary perspectives on the evolution of religion', in F. Watt \& L. Turner (eds.), Evolution, religion, and cognitive science: Critical and constructive essays, pp. 132-151, Oxford University Press, Oxford. https://doi.org/10.1093/acprof:0so/9780199688081.003.0008

Welsch, W., 1996, Vernunft: Die Zeitgenössische Vernunftkritik und das Konzept der Transversalen Vernunft, Suhrkamp Taschenbuch, Frankfurt am Main.

Wuketits, F.M., 1990, Evolutionary epistemology and its implications for humankind, SUNY Press, Albany, NY. 